\title{
Travel behaviour studies facilitate integration of land use and transport planning
}

\author{
K. Puntambekar \\ Department of Planning, School of Planning and Architecture, Bhopal, \\ India
}

\begin{abstract}
Travel behaviour in any city is guided by its land use distribution and transport network and planning. The response of people to the system is travel behaviour. The paper discusses the issues in understanding the travel behaviour of people. The behavioral change in the use of the type of transport is a slow process and can be initiated by providing the infrastructure such that the monetary and temporal benefits are accountable by the user. The inclination towards the use of public transport, walking or other non-motorised transport can be created by integrated land use and transport planning. The two different systems need to work in integration for sustainable development of the urban area. The purpose of the study is to find out how the travel behaviour studies will facilitate the integration of land use and transport planning. With an example the paper will explain how much the travel behaviour depends upon the land use distribution and available transport network.

The conclusion of the study states that there is a substantial amount of dependence of the travel behaviour on land use and transport planning. It also puts forward the issues to be addressed to facilitate the integration of land use and transport planning for reduction of use of motorized transport and to promote the use of public transport, walking or other non-motorised transport. Keywords: travel behaviour, land use and transport planning.
\end{abstract}

\section{Introduction}

The transport of people answers their desire to participate in different activities (like living, working, shopping and recreating) in different places. Land-use patterns therefore would seem to have a potentially large impact on transport. 
Travel behaviour is one of the aspects of the relation between land use and transport. The concept of finding the relation between the land use and travel behaviour is important because they depend on human activity and is responsible for the movement of traffic. Land use defines the location to be reached and travel behaviour defines how it is to be reached. Thus it can act as a decision making tool while (assigning) changing any land use, while assigning a new/ altering the old transport system. The travel behaviour can be made to change by bringing change in either land use system or transport system. In the present urbanisation context the relation holds good as a state-of-art approach in reducing congestion of ever growing urban areas.

Urbanisation has impact on systems, needs to be understood before endeavoring in to them.

\subsection{Impacts of urbanisation: on transport}

The vicious cycle of urbanisation makes it difficult to identify the prior existence of land use or transport system. They occur hand in hand with each other. With advent of new transport systems the spread of urban land use is increasing and vice-versa is also true. The vicious cycle in figure 1 explain the continuous growth of urban area (Puntambekar and Sharma [1]).

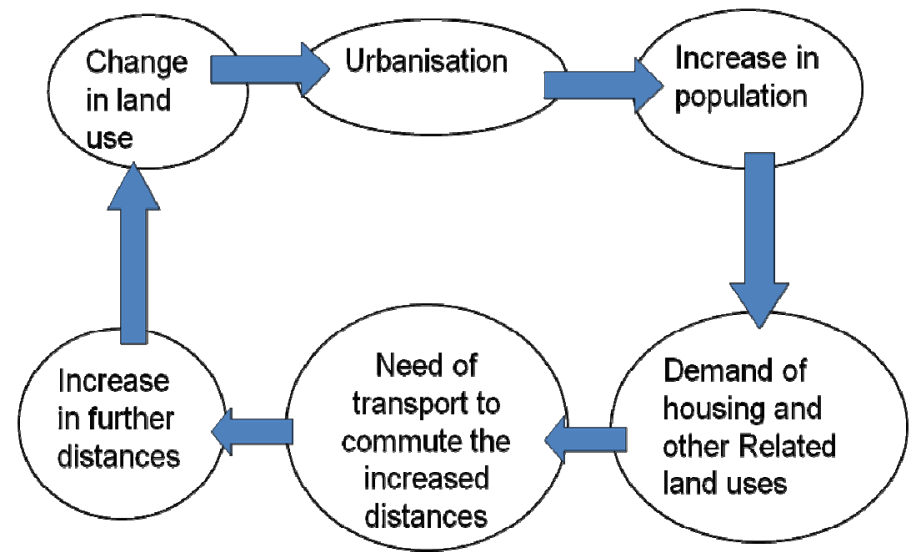

Figure 1: $\quad$ The vicious cycle.

\subsection{Impact of urbanisation: traffic congestion}

As more and more people move to the edge of towns and cities, traffic congestion may get worse. This is because many people try to drive their cars each day into the city for work. Traffic congestion is made worse by the fact that the roads in the centre of urban areas are old and narrow. People are brought into city on large roads or motorways. These roads then link up with smaller, older, narrower roads in the city centre. This causes bottlenecks and congestion. 


\subsection{Impact of urbanisation: travel behaviour}

The impact of growth and change in land use is rightly seen on the behaviour of travel adopted by the people. The technology, means of communication and affordability are adding to the behavioural change in travel. The variety of modes available for travel gives the passenger a choice to decide depending upon different circumstances. The behaviour is very difficult to quantify, but if done so will be of great help to the planners. This may help planners to develop plans based on authentic data which would lead to better results. The travel behaviour also varies between cities, their class, culture and geography. Further in the study the researcher has attempted to measure the impact of different variables such that study will be helpful to both urban planners as well as transport planners.

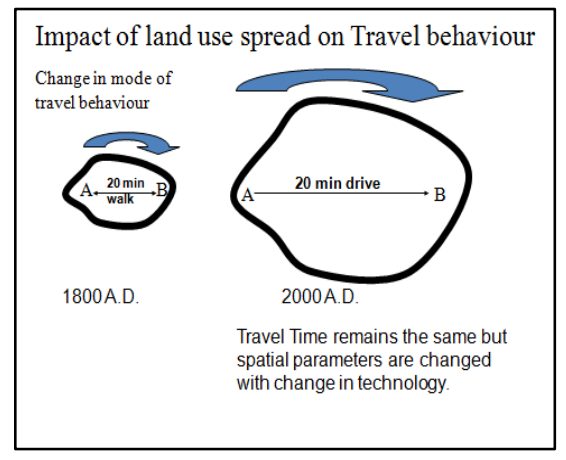

Figure 2: $\quad$ Impact on land use and travel behaviour.

It is essential to comprehend a panoramic observation of the recent trends in the country in general and the study area in particular to assist the advancement of planning process.

One of the most accepted aspects of urban form is the relationship between transportation and land use. According to Hanson, "the intimate relationship between transportation and land use is explicitly acknowledged by the fact that at the heart of every city's long-term land use plan is a transportation plan." However, one of the underlying limitations in transportation/land use planning is that we have yet to fully define the relationship between these two key elements of urban form (Giuliano [2]). This limitation primarily stems from the fact that urban systems are complex and "notoriously difficult to simulate" (Moore and Thorsnes [3]). Although there is disagreement about the strength of the transportation/land use relationship (Giuliano [2]), the importance of understanding it has grown in recent years as major cities grapple with increasing congestion and its concomitant external impacts including air quality and climate change (Woudsma and Jensen [4]).

According to Moore and Thorsnes "We cannot explain how land develops without a description of the characteristics of the transportation system. But the pattern of land use (and activity patterns) feeds back to influence the characteristics of the transportation system." This long recognized mutually 
interdependent relationship between transportation and land use has prompted research from three different perspectives. As per Kelly [5] the interdependence is tested at three levels.

- The influence of transportation on urban development patterns (Land Use),

- The influence of land use (urban activity) on the transportation system and

- The interrelationship between transportation and land use through the use of integrated models

Travel behaviour is the outcome of the human response to land use and transport system (Ewing and Cervero [6]). The relation between the land use system and the travel behaviour should be worked out to define the relation between the two key elements of urban form. The travel behaviour is governed by the spatial and socio-economic impacts of accessibility and land use on each other and vice versa.

Today a lot of time and money is spent on daily commuting of any person to different locations. There are many forces that affect the commuting pattern. The traffic generated on roads is due to the movement of population between work place, leisure and residence. In the present work research will be focused to achieve the relation between land use and travel behaviour to facilitate the land use and transport planning.

Some of the attributes of land use and travel behaviour will be delineated to facilitate the study. The conceptual model in Figure 3 illustrates the significance that both urban form factors (density and land use mix) and non urban forms (income, gender, occupation and age) have on travel behaviour.

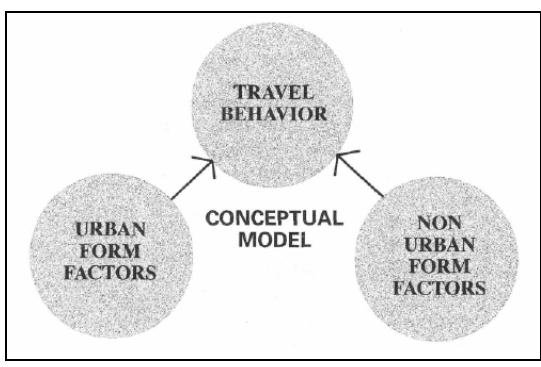

Figure 3: Conceptual model of relation between travel behaviour, urban and non-urban forms. Source: Cervero and Kockelman [7].

Travel behaviour is subjective to land use, land forms and functional aspects of the city. The travel distance increases with the increase of the share of vacant land. The zones with more vacant land exhibit longer trips, zones that are fully developed exhibit smaller and frequent trips.

Consider a zone with number of wards in it. Most of the data in Indian context is available at ward level. Hence we take ward as a unit. Land use distribution is also considered as ward level. All socio economic data is available at this level through census data. Each zone was sampled for requisite data from 
each ward to get the relevant travel behaviour data. The travel behaviour parameters considered are distance, duration, mode and frequency. It was found that the distance and duration parameters were decisive for mode and frequency of travel.

The paper supports that there is a relation in land use and travel behaviour. The travel pattern in old and developed areas characterise less distance to travel. The travel patterns in fringe area characterise more distance to travel. The researcher has identified a method to quantify the distance of travel and duration of travel with the help of a model. Findings from the research on measure of the travel behaviour have identified a pattern followed for distance, duration, mode and frequency of travel in all the zones in Bhopal. All these parameters in the area under consideration will provide data for decision making.

\section{Significance of study area}

Most of the Indian cities were earlier a province and later developed as urban centers. Urban centers have the characteristics of the old city as well as the newly developed planned areas where they exist together and maintain their individuality. Their coexistence reveals typical travel behaviour. The present study area is also one of them.

Bhopal is the capital of Madhya Pradesh. It is also called the city of lakes. It is evolved through stages and presents a different urban fabric in each stage. It is a unique opportunity to study these various settlements which are individually and collectively present in different Indian cities. Six such zones are identified for the study.

After the statistical calculation (correlation regression and sensitivity analysis of data) following results are seen in all zones.

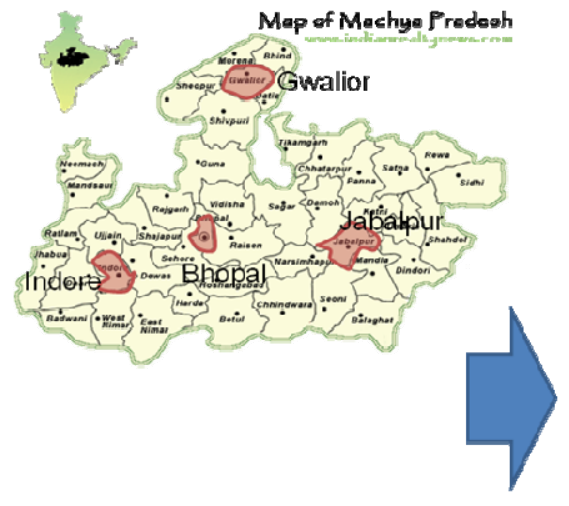

City of Bhopal

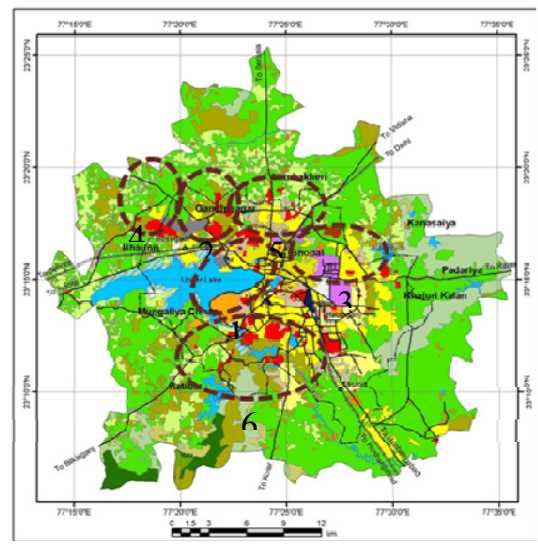

Figure 4: Study area Bhopal. 
The regression for each variable for travel behaviour was carried out. The table below shows the measure of impact in each zone on the travel behaviour variable as dependent variable. The impact measure for each activity is tabulated below. Land use impact is most in zone 3 (BHEL zone) and least in Zone 2 (Old Bhopal).

Table 1: Impact of land use variables of each zone on travel behaviour variables.

\begin{tabular}{|c|c|c|c|c|}
\hline zone & mode & duration & distance & frequency \\
\hline 1 & 2.9 & 6.7 & 2.1 & 9.4 \\
\hline 2 & 0.1 & 0.6 & 0.2 & 0.5 \\
\hline 3 & 3.9 & 17.6 & 4.2 & 1.4 \\
\hline 4 & 2 & 0.4 & 0.6 & 0.2 \\
\hline 5 & 1.2 & 0.8 & 2 & 0.3 \\
\hline 6 & 3.8 & 9.4 & 3 & 1.3 \\
\hline
\end{tabular}

\section{Interrelation of parameters and travel behaviour}

\subsection{Evolution of city and travel behaviour}

The urban form is a dynamic entity and thus does the travel pattern. The 6 delineated zones present a unique character and travel pattern. It is observed that "zone 2 old Bhopal" has very high density and mixed land use is prominent. Many wards have high percent of commercial and mixed land use. More than $60 \%$ of the work trips are on foot or cycle. "Zone 1 " houses the new development of Bhopal as a capital. Here two wheelers and four wheelers make more than $50 \%$ of the total trips. This has generated typical travel behaviour in each zone. The trips have a typical pattern which changes in each zone. In zone 3,5 and 6 the use of two wheelers and four wheelers is prominent. "Zone 4 Bairagarh" had developed as a refugee camp in 1947. It has grown as an independent settlement and now is merged in Bhopal. Most of the people reside in the same ward as they work.

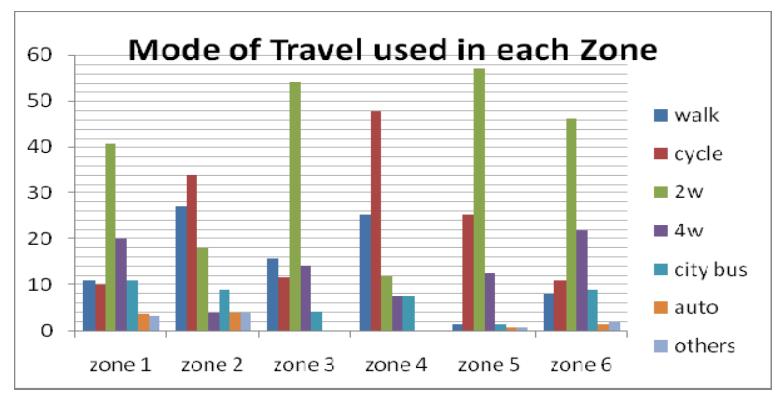

Figure 5: $\quad$ Zone wise modal split (city level). 


\subsection{Activity and travel behaviour}

The activities mentioned in the study represent more use of public transport for travel for leisure, market and other activities. When the travel is to work place, personal vehicles are used. For Leisure activity, public transport and four wheelers are used.

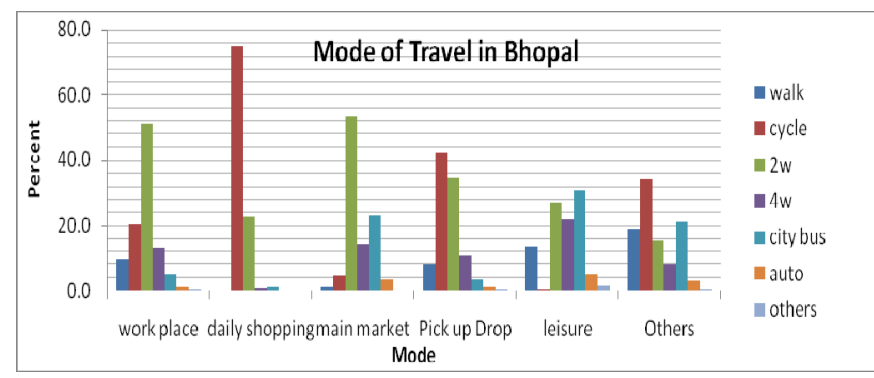

Figure 6: $\quad$ Activity wise modal split (city level).

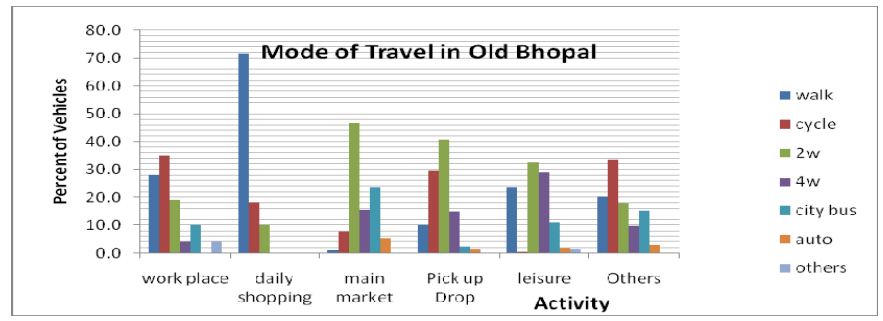

Figure 7: $\quad$ Activity wise modal split (zone level).

\subsection{Distance and travel behaviour}

The distances of travel to work place in zone 1 are evenly distributed in all ranges. Zone 4 show that travel distance is within two kilometres. In zone 5, travel for the distance of five to ten kilometres is $38.1 \%$ and above ten kilometres is 7\%. "Zone 5 South Bhopal" is a sprawl and the work place is not in the same zone.

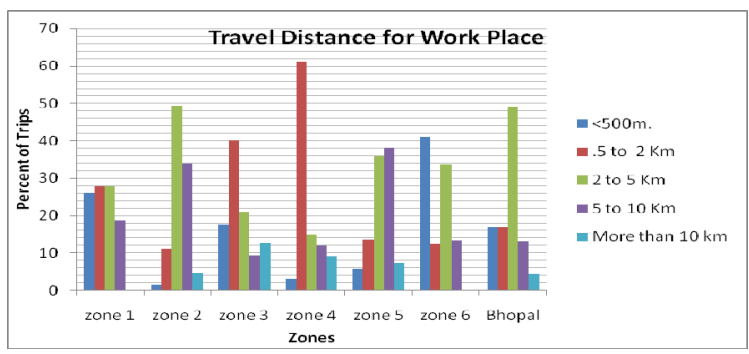

Figure 8: Distance of travel to work place in each zone. 


\subsection{Duration and travel behaviour}

In Bhopal city $51.4 \%$ of trips for work place are of 15 to 30 minutes duration. In zone $2,72.5 \%$ of trips are of 15 to 30 minutes duration. This is because of the collective effect of road widths, the traffic volume and land use distribution. The time of travel and direction of travel to work place is same due to concentration of similar land uses resulting in the increase in duration of travel. Travel duration is more than 30 minutes in most of the trips in zone 5.

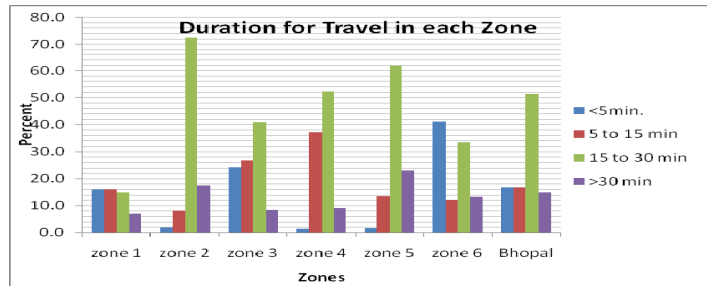

Figure 9: Duration for travel to work place in each zone.

\subsection{Density and travel behaviour}

Among all the zones Density of zone 2 is highest (400pph), density in zone 3 is lowest (96pph). In zone 2, distance of travel is less due to high density. The mode of travel is non-motorised. In zone 3 the distance of travel is more due to low density. The maximum preferred modes of transport for work are two wheelers and four wheelers. At the same time; the duration of travel for same distance is less in low density area and more in high density area.

\subsection{Diversity in land use distribution and travel behaviour}

In zone 5 the residential area is more than $50 \%$ and area under transport is $18 \%$ of the developed land. People need to travel more for all activities in this zone. Commercial activities are concentrated in some wards which attract the traffic.

\subsection{Effect on distance in zone 2 old Bhopal}

With the increase in percentage of land use variables specifically, transport/ open, the travel distance increases. And, with the increase in percentage of land use variables specifically residential/ commercial/ public/ vacant land use, travel distance decreases. The extent depends on the cumulative effect of the composition of land use which is reflected in figure 10. The land use distribution changes at ward level. Figure 11 shows that travel distance is maximum in ward number 6 and10. Land use distribution of these wards are (ward 6 resi 18\%, com $6 \%$ mix $5 \%$ public $45 \%$ open $15 \%$ and trans $11 \%$ and in ward 10 resi $60 \%$, com $5 \%$ mix $5 \%$ public $5 \%$ open $8 \%$ and trans $16 \%$ ).). Ward number 21 shows min travel distance, land use distribution of this ward is (resi $2 \%$, com $54 \%$ mix $28 \%$ public $4 \%$ open $3 \%$ and trans $9 \%$ ). 


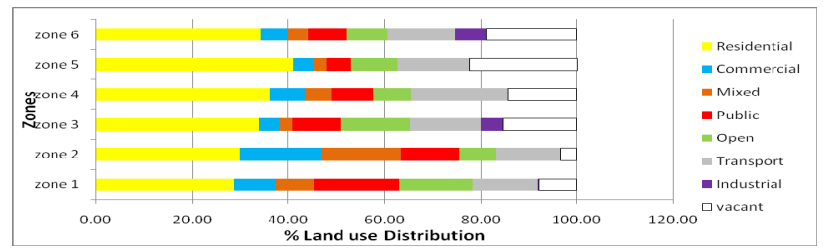

Figure 10: $\quad$ Land use distribution (zone level).

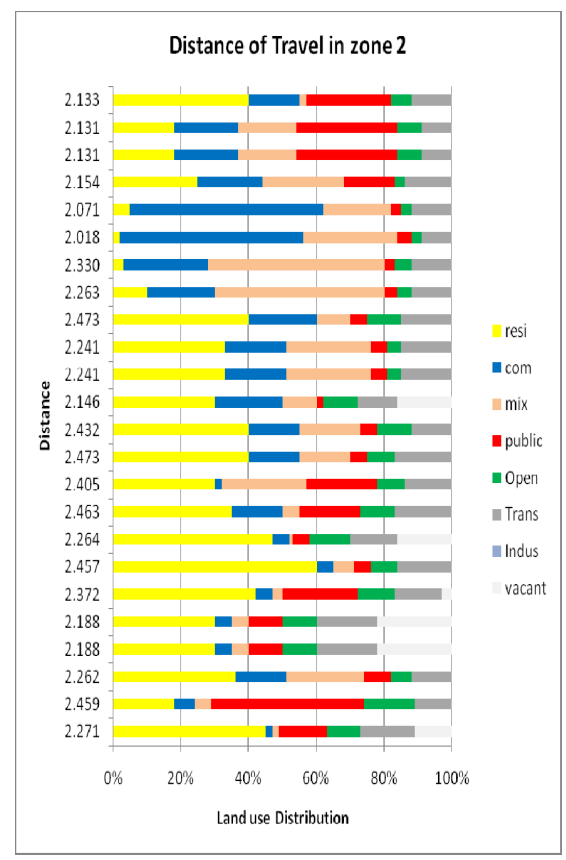

Figure 11: Sensitivity analysis chart showing impact of land use distribution on distance of travel (zone 2).

\subsection{Socio-economic characteristics and travel behaviour}

Amongst the variables into consideration for travel behaviour study, the socioeconomic characters have the highest impact on the choice of mode. The economic capacity of the individual decides the mode one can use. The socially and physically distressed areas will have cycles and walk as major mode.

\subsection{Transport network and travel behaviour}

For smaller distances the public transport is not used in Bhopal and people rely more on personal transport. The frequency of public transport and their stops need to be revised as per many respondents during the survey. Result of study assists the implementation of efficient public transport. 


\subsection{Policy decisions for physical planning}

The relational study presents the picture of travel behaviour in the study area. This assists in decision making for the physical development of the area. This empirical research can be used for policy decisions for land use distribution (renewal or redevelopment in existing areas and planned development for proposed development) in urban area. Areas with similar characteristics can be treated as one zone. It is observed that behaviour pattern changes with the density and diversity of land. The study will facilitate in decision making for altering the densities and diversities at macro level (city), and identifying the sites when approached at the micro level (ward).

While forming the policies of redevelopment of any area, the influence of each land use in that area can be interpreted by the model thus developed using the data which is easily available.

\subsection{Policy decisions for transport and environmental planning}

The National Urban Transport Policy (NUTP) in India emphasises on coordinated land use and transport planning. The behavioural pattern projected in the study will assist in decision making for the selection of transport systems appropriate for the study area. The policy decisions can also be taken for

- Road widening

- Congestion reduction

- Modes for public transport

This research is helpful in deciding multimodal transport system and to predict the travel behaviour of certain spatial setup.

For coordinated land use and transport planning, measuring the relation of land use and travel behaviour will be of great help.

\section{Conclusion}

The results which were observed during the Travel behaviour study show that land use distribution has a small but sure and measurable contribution in generation of trips. Land use distribution has considerable effect on the distance and duration of travel. In each of the zones the impacts of land use distribution is different. The extent of impact by individual land use is limited. The combined effect of the land use distribution is evident. Travel behaviour studies will facilitate the integration of land use and transport planning. The research will assist in the policy decisions for the development of the urban areas and create healthy liveable cities.

\section{References}

[1] Puntambekar K. and Sharma A (2006) Need of Integrated Land Use and Transport Planning International Conference "Eco-city 6" 
[2] Giuliano, G., "Land Use Impacts of Transportation Investments, Highway and Transit"; in S. Hanson and G. Giuliano (Eds.), The Geography of Urban Transportation, 3rd edition. New York: Guilford Press; 2004

[3] Moore, T. Thorsnes, P (1994) The transportation/land use connection: A framework for practical policy American Planning Association, Planning Advisory Service NA9108.A545 no. 448-449

[4] Woudsma C.G. and J.F. Jensen (2003) Transportation's Influence on Land Use Development: A Historical Spatial-Temporal Approach, Transportation Research Board, Washington D.C.

[5] Kelly E. D.(1994), The Transportation Land-Use Link, Journal of Planning Literature, Vol. 9, No. 2, November 1994, p. 128-145.

[6] Ewing, R. and Cervero R. (2001) Travel and the Built Environment. Transportation Research Record 1780, Transportation Research Board, National Research Council, Washington, D.C., pp. 87-114

[7] Cervero, R and Kockelman K. (1997). Travel Demand and the 3Ds: Density, Diversity, and Design. Transportation Research D, Vol. 2, No. 3. Pp 199219 